\title{
Chiloé en otro lugar. Memorias de migraciones a Punta Arenas ${ }^{1}$
}

\author{
Chiloé in another place. \\ Memories of migrations to Punta Arenas
Katherine Riveros Quinteros ${ }^{\mathrm{a}}$ \& Macarena FernándeZ Génova ${ }^{\mathrm{b}}$
aAntropóloga, bAntropóloga, \\ $><$ katty_rq84@hotmail.com,macarenapfg@gmail.com
}

\begin{abstract}
RESUMEN
Este artículo pretende contribuir a la construcción de conocimientos sobre migraciones chilotas a Magallanes, mostrando resultados de un estudio que estuvo centrado en la reconstrucción de la memoria social de inmigrantes chilotes en la ciudad de Punta Arenas. El trabajo de investigación se apoya en los aportes teóricos realizados desde el campo de la antropología de la memoria y utiliza el relato biográfico de migrantes de Chiloé como un recurso testimonial que permite reivindicar aquellas memorias anónimas y subterráneas. Asimismo, el artículo expone cómo la memoria social de las personas migrantes de Chiloé se reproduce y expresa en otro lugar mediante distintos elementos materiales e inmateriales que actúan como referentes empíricos de la memoria y de la cultura de un pueblo.
\end{abstract}

PALABRAS CLAVE: Migración, Chiloé, Punta Arenas, Memoria Social.

\begin{abstract}
This article aims to contribute to the construction of knowledge about Chiloe migrations to Magallanes, showing the results of a study that focused on the reconstruction of the social memory of Chilote immigrants in the city of Punta Arenas. The research work is

1 El trabajo presentado forma parte de los resultados de una investigación antropológica realizada en el marco del Proyecto Fondart Regional Folio 420870 "Chiloé en otra parte: Memorias de migraciones y prácticas isleñas en Magallanes", Línea de Patrimonio Cultural, convocatoria 2017. Los resultados del estudio han sido plasmados en el libro Entre mares, pampas y vientos. Memorias de Chiloé en Punta Arenas y en la ponencia Desde Chiloé a Punta Arenas: Relatos de migraciones y prácticas isleñas, presentada en el Museo de Ancud en el seminario Chiloé y su influencia cultural realizado en septiembre de 2017. Ambos escritos han sido el sustento de este artículo.
\end{abstract}


based on the theoretical contributions made from the field of anthropology of memory and uses the biographical account of migrants from Chiloé as a testimonial resource that allows vindicating those anonymous and subterranean memories. Likewise, the article exposes how the social memory of the migrants of Chiloé is reproduced and expressed in another place through different material and immaterial elements that act as empirical referents of the memory and culture of a people.

KEY WORDS: Migration, Chiloé, Punta Arenas, Social Memory.

\section{INTRODUCCIÓN}

La migración chilota a Magallanes ha sido fundacional desde que Chile ejerce soberanía en la región y, por tanto, tiene una impronta histórica. Seguramente por esta causa se ha venido estudiando hace bastante tiempo, sobre todo desde el campo de la Historia. La Antropología (social o sociocultural), por su parte, se ha involucrado tardíamente en el análisis de este fenómeno migratorio. Nos atreveríamos a decir -a riesgo de equivocarnos- que los estudios desde la disciplina antropológica han sido marginales en el tema o -elucubramos- han sido realizados tan silenciosamente que no se han posicionado como referentes de análisis ni en la región de Magallanes ni en Chiloé. Desde la historia encontramos una variedad de publicaciones: Urbina (1988), Martinic (1999), Lausic (2005), Montiel (2010) y Mancilla (2012), entre otros ${ }^{1}$. Desde la antropología es difícil enunciar una lista de investigadores/as. Esto no quiere decir -bajo ningún punto de vista- que no existan trabajos realizados, pero su posicionamiento ha tenido un impacto menos evidente dentro de la literatura de las Ciencias Sociales.

Frente a esto -y a modo de responsabilidad disciplinar- cabe preguntarse entonces en primera instancia ¿Qué implicaría mirar antropológicamente el fenómeno de las migraciones chilotas a Magallanes? Evidentemente los flujos migratorios de cualquier sociedad o grupo social deben analizarse desde las condicionantes históricas, políticas, económicas, ambientales y/o culturales que se encuentran a la base de un desplazamiento humano. La Antropología -como cualquier disciplina de las Ciencias Sociales- tiene ventajas y limitantes dentro de la construcción de conocimientos, pero en cuanto a sus aportes ofrece una manera particular de acercamiento a la realidad social que se traduce en un aporte metodológico, teórico e ideológico. Vale la pena exponer brevemente este argumento para comprender el sentido de la investigación realizada y, en particular, de este manuscrito. Metodológicamente, la Antropología sustenta su quehacer desde la Etnografía, es decir, desde un trabajo de

\footnotetext{
Urbina, R. (1988) Chiloé. Foco de emigraciones; Martinic, M. (1999) La inmigración chilota en Magallanes. Apreciaciones sobre sus causas, características y consecuencias; Lausic, S. (2005) Migraciones del archipiélago de la isla grande de Chiloé hacia la Patagonia (Chile-Argentina) y participación en el sindicalismo obrero; Montiel, F. (2010) Chiloé. Historia de viajeros; Mancilla, L. (2012) Los chilotes de la Patagonia Rebelde. La historia de los emigrantes chilotes fusilados en las estancias de Santa Cruz, Argentina, durante la represión de la huelga del año 1921.
} 
campo que no es solo la aplicación de un conjunto de técnicas (observación, entrevistas, registro audiovisual, etc.) para el levantamiento de información sino un enfoque orientado a la descripción de la cultura de un grupo social mediante el contacto directo. La persona que investiga desde un enfoque etnográfico está obligada a "estar ahí” y a relacionarse con las personas que conforman ese grupo para comprender desde adentro las lógicas que operan en la interacción social. Teóricamente, significa estudiar la cultura, es decir, todo aquello que hace el ser humano, desde la configuración de su mundo simbólico y material hasta su expresión concreta en las prácticas cotidianas. Ideológicamente, implica asumir una posición respecto al grupo estudiado, ya sea para fortalecer su compromiso con esa población, para relevar la condición humana detrás de fenómenos sociales complejos y/o para contribuir en la lucha por el reconocimiento de ciertos grupos.

Lo anterior implicó que este estudio se efectuó teniendo en consideración dichos aportes de la disciplina antropológica, porque metodológicamente el levantamiento de información tuvo como foco a las personas migrantes, sus discursos y sus prácticas; teóricamente implicó estudiar la cultura de un grupo migrante en Magallanes en cuanto a las rupturas y continuidades que supone el proceso migratorio y la radicación en un nuevo lugar; ideológicamente significó reivindicar la historia social de los y las migrantes de Chiloé radicados en una ciudad magallánica porque, al representar a una cierta clase social, han sido un grupo relegado dentro de la historia e identidad regional y no han tenido el mismo protagonismo que otros grupos migrantes provenientes del "viejo continente". Tensionar la memoria dominante y privilegiar el discurso de los excluidos, de los grupos minoritarios, de las memorias subterráneas es, en ese sentido, asumir una posición ideológica. Por lo mismo, y en función de los aportes disciplinares, la reconstrucción histórica del desplazamiento desde Chiloé a Punta Arenas se realizó desde las personas anónimas que han protagonizado dicho fenómeno migratorio, es decir, desde el relato oral de migrantes isleños y desde la observación de lo que la gente hace en el lugar de destino. Ambos niveles -el relato oral y la práctica- engloban un concepto más amplio: el de la memoria -social o colectiva- que es el enfoque teórico de este trabajo y permite situarlo dentro del campo de la Antropología de la memoria.

Delimitado el enfoque cabe preguntarse ¿A qué nos referimos cuando hablamos de memoria? Claramente no nos referimos a la condición cognitiva y neuropsicológica del ser humano en cuanto a facultad individual para recordar situaciones, acontecimientos, sensaciones y acciones. Por el contrario, nos referimos al carácter esencialmente social y compartido de la memoria, que dice relación con la manera en que los grupos sociales recuerdan, olvidan o se apropian del conocimiento del pasado social y donde lo social, a su vez, juega un papel fundamental en la memoria auto-biográfica, es decir, en las subjetividades; por ende, no hay memoria que no sea social.

Halbwachs (2004), quien acuña el concepto de memoria colectiva y rompe con la tradición que entendía la memoria como una facultad individual, señala que la memoria 
como reconstrucción dinámica del pasado está condicionada por aquellos marcos sociales que le sirven como puntos de referencia para la localización del recuerdo, es así que entre grupo social y recuerdo existe un vínculo indisociable. Baer (2010), apoyándose en Halbwachs, argumentaría que “cada 'yo' está conectado a un 'nosotros' por lo que su recuerdo se forja en la interacción con el grupo o grupos de pertenencia (la familia, la comunidad escolar, la profesión). La memoria individual de cada persona está inmersa en un horizonte de interpretación sociocultural que determina y también posibilita su propia actividad de recuerdo" (Baer, 2010, p. 132).

Un aspecto clave para comprender la especificidad de la memoria colectiva tiene relación con la historia vivida porque el testimonio experiencial "tiene todo lo necesario para constituir un marco vivo y natural en el que un pensamiento puede apoyarse para conservar y encontrar la imagen de su pasado" (Halbwachs, 2004, p. 71). El mismo autor diría que no es sobre la historia aprendida sino sobre la historia vivida que se apoya nuestra memoria. Esta perspectiva es un componente clave al momento de situar el presente trabajo de investigación, porque constituye su fundamento teórico-conceptual y también metodológico al hacer uso del método biográfico para la reconstrucción y comprensión de las migraciones chilotas a la ciudad de Punta Arenas y para la elaboración de una matriz de georreferenciación que permitiera situar la presencia e influencia chilota dentro del plano urbano. Aspectos metodológicos que serán expuestos en el siguiente punto. Por ahora importa insinuar que con este trabajo no se trata de efectuar un "culto a la memoria", pero no podemos soslayar que nos basamos en las memorias (las viejas o nuevas memorias) para dar sentido a nuestras vidas.

La memoria colectiva es dinámica y reconstructiva porque, al estar anclada en el presente del grupo social que recuerda, está sujeta a un constante cambio, reelaboración y filtrado. En consecuencia resulta significativo preguntarse, ¿Cómo un grupo social recuerda? ¿Qué estrategias emplea para perpetuar en el tiempo su memoria colectiva? Baer (2010) enuncia que existen distintos elementos que permiten "contener" la memoria, tales como: espacios de memoria, monumentos, aniversarios y conmemoraciones, testigos y testimonios. "La memoria social requiere lugares y tiende a su espacialización (...) son símbolos de su identidad y puntos de referencia de su recuerdo" (Baer, 2010, pp. 136-137), ejemplo de aquellos son los templos o iglesias; los monumentos, por su parte, son reconocidos como un lugar de memoria por excelencia, sin embargo y contrariamente, señala que tienden a normalizar y a embalsamar la memoria, haciéndola imperceptible; los aniversarios y conmemoraciones representan la dimensión temporal de la cultura del recuerdo donde ciertos acontecimientos han sido declarados dignos de ser recordados, reevaluándolos desde el presente y expresándolos a través de un conjunto de prácticas ritualizadas cargadas de un valor simbólico; por último, testigos y testimonios que son elementos significativos por cuanto permiten "democratizar" la historia, porque "toman la palabra quienes antes estaban excluidos de ella" (Baer, 2010, p. 144). Cabe anticipadamente mencionar que los argumentos del autor han inspirado el trabajo 
de georreferenciación realizado en el marco de la investigación.

La memoria tiene un anclaje en el tiempo y en el espacio. Y cuando hablamos de grupos migrantes la memoria no solo es colectiva sino que también es una memoria territorializada, porque el recuerdo se sitúa desde aquel espacio territorial de origen que ha sido dominado (político-económico) y/o apropiado (simbólico) por el colectivo, es decir, donde la vida de un grupo ha sido reproducida y, por tanto, ha sido un componente clave para forjar su identidad social.

La memoria colectiva de un grupo migrante recurre constantemente al territorio originario y lo replica, lo resignifica, lo adapta culturalmente e incluso lo "camufla" en el lugar de destino para perpetuarlo en el tiempo. En la memoria territorializada (que no es solo perteneciente a los grupos migrantes) hay también una memoria del apego, del arraigo, de la pertenencia, de lo identitario. $\mathrm{Y}$, a veces, en el territorio de destino esas memorias se transforman en una memoria olvidada, negada, encapsulada, silenciada y/o subyugada; así como existen memorias hegemónicas existen también memorias subalternas que, en ciertas efervescencias o momentos de la historia social, disputan un lugar de reconocimiento dentro del espacio social. Pollak (2006) habla de la existencia de memorias subterráneas que como parte integrante de las culturas minoritarias o dominadas se oponen a la memoria oficial y "esas memorias subterráneas prosiguen su trabajo de subversión en el silencio y de manera casi imperceptible afloran en momentos de crisis a través de sobresaltos bruscos y exacerbados. La memoria entra en disputa" (Pollak, 2006, p. 18).

En el caso de las migraciones a Magallanes es posible reconocer que los distintos grupos migrantes que se asentaron en el territorio patagónico (chilotes, croatas, españoles, británicos, suizos, por ejemplo) han realizado un juego diferenciado en cuanto a sus memorias, ya que no todas se han posicionado en igualdad de condiciones o de reconocimiento dentro de la región.

En cuanto a la memoria colectiva territorializada es importante entender que en los grupos migrantes existe un diálogo, más o menos tensionado, entre el lugar de origen y el de destino que permite, consciente o inconscientemente, la conformación de un "nuevo territorio" que, inspirándonos en los conceptos de lugar y no-lugar de Marc Auge (2000), hemos denominado otro lugar.

El otro lugar es siempre un lugar culturalmente en contradicción entre el pasado y el presente, entre la continuidad y el cambio, entre lo antiguo y lo nuevo, entre lo propio y lo ajeno. El otro lugar es un espacio en creación constante desde la tensión y la negociación de los diferentes referentes culturales que entran en diálogo. Evidentemente un otro lugar no es un espacio del anonimato, es decir, un no-lugar, por el contrario, es un espacio nuevo de re-producción de la vida social y material, de re-significación de la vida colectiva y de reconstrucción de la memoria colectiva territorial. Ese volver a producir, significar y construir la vida social en otro lugar supone un juego contradictorio entre el origen y el destino, entre lo que fuimos y lo que seremos. Y según Joel Candau (2006) solamente la memoria permite ligar 
lo que fuimos con lo que seremos, solo ella puede ayudar a conceptualizar el paso inexorable del tiempo y así aceptarlo. Por lo mismo, las migraciones chilotas estudiadas desde el ámbito de la memoria han sido un recurso que no solo permitieron reconstruir el pasado de aquellos desplazamientos territoriales, sino también el presente de un grupo social.

\section{METODOLOGÍA}

El trabajo de investigación se enmarcó dentro de un enfoque cualitativo, cuya prioridad estuvo puesta en entender el contexto y el punto de vista del actor social. La investigación fue un estudio descriptivo que estuvo centrada en dar cuenta cómo ha sido el proceso migratorio de personas de Chiloé que se encuentran residiendo en Punta Arenas; cuáles han sido las motivaciones y razones para salir del archipiélago y radicarse en una ciudad magallánica, en qué momento se migra; cuáles son las características de esas migraciones; y cómo se reproduce parte de la vida social, económica y cultural de Chiloé en otro lugar.

Se realizaron entrevistas en profundidad, a modo de relato biográfico, a 16 personas chilotas, existiendo una muestra equitativa de 8 hombres y 8 mujeres. La edad de los hombres fluctúa entre los 79 y 30 años, proveniendo de lugares como Notuco, Linao, Coihuinco, Quilquico, Terao, Quemchi, isla Chelín y Chonchi; migrando de Chiloé en los años 1957, 1960, 1967, 1982, 1986, 1996, 1998 y 2005. Las mujeres, por su parte, se sitúan en un rango de edad que va desde los 88 a 26 años, mientras que sus lugares de origen son Tenaún, isla Quenac, Gamboa, Palqui, Aldachildo, Chonchi, Caulín y Notuco; migrando de Chiloé en los años 1949, 1957, 1966, 1968, 1969, 1970, 1977 y 2009.

La muestra del estudio es de carácter no probabilística; la selección de las personas se realizó principalmente bajo cuatro criterios intencionales: 1) que hayan nacido y vivido por lo menos 10 años en Chiloé; 2) que algunos hayan sido representantes de organizaciones chilotas en Punta Arenas; 3) que tengan diferencias generacionales entre sí; y 4) que se cumpla una cuota equitativa de género para recopilar la misma cantidad de relatos de hombres y de mujeres.

Deformaparalelaalaaplicación deentrevistas serealizóun ejercicio degeorreferenciación para visibilizar la presencia de Chiloé en la ciudad de Punta Arenas. Se elaboró una matriz considerando diferentes dimensiones (arquitectónica, urbanística, organizativa, económica y simbólico y social) ${ }^{3}$ para observar elementos tangibles e intangibles de la cultura isleña en la ciudad. Se observaron lugares de encuentros de la comunidad chilota en Punta Arenas, por ejemplo, el santuario Jesús Nazareno en cuanto arquitectura, historia, lugar de encuentro y ritualidad; el Centro Hijos de Chiloé en cuanto grupo organizado, gastronomía tradicional chilota y la festividad para la noche de San Juan; la Fiesta Costumbrista de Chiloé realizada por la Agrupación de Conjuntos de Chiloé (ACOCHI) en el mes de Febrero, el Cementerio

La denominación y categorización de estas dimensiones (arquitectónica, urbanística, organizativa, económica y simbólico y social) se realizó en el contexto de la investigación. 
Municipal de Punta Arenas donde se aprecian tumbas con imágenes de Jesús Nazareno, las cuales replican la arquitectura mortuoria de los cementerios rurales de Chiloé; se observan calles con apellidos de origen chilote como Los Oyarzún, Los Mansilla, Los Colivoro o Chilote Díaz en referencia a un corregidor de la zona que era originario de Chiloé; monumentos como la Goleta Ancud o El Ovejero; y distintos negocios de gastronomía chilota.

\section{CHILOÉ EN OTRO LUGAR - MEMORIAS TERRITORIALIZADAS DE MIGRANTES}

Este apartado tiene por objetivo mostrar resultados de la investigación. En primer lugar, describir el proceso migratorio Desde Chiloé a Punta Arenas mediante un ejercicio de la (s) memoria (s) cuyo anclaje estuvo situado en el relato de vida como testimonio oral del desplazamiento territorial. Su sentido es recuperar las historias de migraciones chilotas desde las personas anónimas que han protagonizado dicho proceso. Lo anterior porque son historias que permiten comprender que existen factores transversales a las distintas épocas y generaciones de migrantes, pero cada historia presenta también sus particularidades que enriquecen la mirada y a la vez la complejizan. Los temas a describir -basándonos principalmente en la memoria oral- refieren a los recuerdos de vida en el lugar de origen, a los motivos para migrar, a la radicación en Punta Arenas, a la discriminación sufrida en la ciudad magallánica y a la identidad, a eso que llaman ser chilote/a. Por otra parte, el objetivo de este apartado es mostrar cómo la memoria social de las personas migrantes se materializa y reproduce en Punta Arenas mediante un conjunto de elementos observables en la ciudad. En particular, nos centraremos en la gastronomía chilota y en las celebraciones rituales (Noche de San Juan; la Novena y Procesión de Jesús Nazareno) como expresiones de un juego contradictorio entre las rupturas y continuidades culturales de un Chiloé manifiesto en otro lugar, un Chiloé que se sincretiza en lo magallánico y un Magallanes que se sincretiza en lo chilote.

El lugar de origen antes y después de migrar: Memorias de la vida social y económica en Chiloé

Evocar la vida social y económica de un lugar supone por parte de la persona migrante no solo una reconstrucción vivencial de un mundo pasado sino también del presente, es decir, de aquellas dinámicas territoriales que cambian y/o se perpetúan a lo largo del tiempo. Para el caso de esta investigación se pueden dimensionar dos momentos interrelacionados en que se expresa testimonialmente la memoria colectiva respecto a la vida social y económica del archipiélago. Uno referido al recuerdo del lugar antes de migrar, es decir, a la experiencia de vida cotidiana en el territorio de origen y otro alusivo a Chiloé narrado desde afuera, es decir, cuando se es migrante y, por ende, no se vive cotidianamente en el lugar de origen.

En relación a Chiloé antes de migrar se puede apreciar que las personas migrantes cuando narran sus recuerdos experienciales de la isla, independiente del género y la edad, 
evocan a un mundo rural donde los grupos domésticos, antes de la década de los 80, estaban ligados en exclusividad a las actividades de la tierra y del mar. El trabajo productivo estaba vinculado principalmente al cultivo de la papa y del trigo para el autoconsumo y en menor medida para la comercialización. Aquellas actividades campesinas eran complementadas con la ganadería, la explotación maderera y la pesca para el auto-consumo del grupo familiar.

"Me dediqué a la agricultura, sembrábamos papas, trigo, habas, arvejas; se criaban las ovejas, los cerdos, pavos, patos, gansos, de todo. La gente en Chiloé trabaja principalmente en agricultura. Mi papá tenía una máquina aventadora para separar la paja y el trigo; trabajaba con mi papi, recorríamos todos esos sectores aventando el trigo de la gente, y el que no tenía plata para pagar el trabajo pagaban en trigo" (Mujer, 69 años, migró en 1968) ${ }^{4}$.

“Sembrábamos papa, trigo, avena y forraje para los animales, (...) me metía a mariscar con la gente que sacaba la famosa macha que llaman Conquihuen; también íbamos, a una parte que se llama Pilol, a sacar locos. Esos se desconchaban, se secaban y se guardaban para el invierno" (Hombre 77 años, migró en 1957).

Del Chiloé rural vivido recuerdan también aquellas prácticas culturales, domésticas y cotidianas que definen al lugar de origen. Desde la comida, las actividades sociales y comunitarias hasta las celebraciones rituales emergen como elementos de anclaje a un terruño lejano. En el discurso resurge con nostalgia la minga, el medán, el reitimiento del chancho, la preparación del lloco, de la chochoca, del chopón o tropón para la noche de San Juan, la maja de manzanas o procesiones religiosas como la Virgen de la Candelaria o Jesús Nazareno de Caguach.

"Allá la gente se reunía en un santo, San Juan, San Pedro, esos eran los santos más importantes para la gente de la isla de Chiloé. Se hacían malones. Para la noche de San Juan en mi casa hacían. Por ejemplo, el 24 es la noche de San Juan; el 22 había un chancho especial que se carneaba; 23 empezaban a cocinar la carne, llegaban los invitados para ir a comer en la noche de San Juan: papas, milcao, sopaipillas, tropones" (Mujer, 63 años, migró en 1970).

"Lo otro que se hacía eran fiestas para ayudar al vecino. La minga era normal, pero también estaba el medán. Consistía en que la familia en decadencia hacía una cena. Los vecinos participábamos; no se daba plata, se entregaba una oveja, una vaquilla, un par de chanchitos nuevos para que la gente se arme y tengan para seguir viviendo el resto del año" (Hombre, 77 años, migró en 1957). 
Aquellas personas que migran en las últimas décadas, principalmente desde los años '90 en adelante, refieren las contradicciones de un Chiloé en constante tensión con la modernidad y su sistema económico, cuya ideología capitalista se manifiesta en la presencia desbordante de la empresa acuícola y salmonera en cada rincón del archipiélago. Las actividades del mundo rural son reemplazadas por aquellas vinculadas a la industria. Tanto los hombres como las mujeres se integran a un mercado laboral que los convierte en personas asalariadas.

"Mi mamá trabajó como operaria en las pesqueras, armando carnada para la pesca con espineles (...) En este mundo acuícola había mucho abuso a los trabajadores. En una de las faenas de cosecha de salmones estuve en un lugar que se llamaba Terao, trabajábamos casi catorce horas en el día” (Hombre, 32 años, migró en 2005).

"En ese tiempo, el trabajo más sustentable era en las pesqueras, entonces mi papá trabajaba para la salmonera en la mantención y reparación de todo lo que era estructura metálica; y mi mamá trabajaba en un internado haciendo la comida a los que pernoctaban ahí. Mis papás arrancaron de Chiloé en 1995, antes de la crisis del salmón. Vinieron a Punta Arenas a buscar una mejor vida” (Hombre, 30 años, migró en 1996).

Chiloé después de migrar es apreciado como un territorio distinto al lugar habitado. Dicha percepción se sustenta en los cambios concretos observados por las personas migrantes cuando han vuelto a la isla o por lo que han escuchado, ya sea por sus coterráneos o a través de los medios de comunicación. Las transformaciones territoriales refieren principalmente a aspectos de la modernidad traducidos en la conectividad, en la construcción y pavimentación de caminos, en el impacto del turismo en la isla y en la generación de nuevos nichos de trabajo que ha implicado un abandono y disminución de las prácticas económicas tradicionales. Para las personas entrevistadas, Chiloé ha cambiado y su transformación ha sido evidente, principalmente para quienes migraron de la isla antes de la irrupción de las empresas salmoneras.

“Yo hasta como los 30 años viví en Chiloé, siempre estuve en el mismo lugar (...) Era campo, pero ahora está todo reformado; antes no pasaban vehículos a la orilla de las puertas y ahora ya no siembran papa ni trigo porque está muy mal pagado" (Mujer, 77 años, migró en 1969).

“A Chiloé volví el año '87 casado y con una hija. Lo encontré diferente y cada año ha ido cambiando. Chiloé ha progresado muchísimo, en lo que es conectividad. Antes, en la ciudad no había semáforo, la pavimentación de las calles era poquísima, para ir al campo eran puros caminos de ripio, ahora está todo asfaltado" (Hombre, 54 años, migró en 1982).

"El tema que obviamente se ha ido perdiendo mucho de eso, de la ayuda (...) de las 
mingas, porque no hay mucha gente y la gente trabaja por un sueldo fijo, actualmente, por eso la gente se fue a la salmonera o se fue a otro rubro y no trabaja en el campo, porque trabajar en el campo es mucho más esforzado, tienes que levantarte temprano, ver los animales, sacar papas y estás todo el día ahí con la cintura echa bolsa (...) entonces el tema de la minga se ha ido perdiendo un poco en Chiloé" (Mujer, 26 años, migró en 2009).

Salir del origen: Motivos de las migraciones a Punta Arenas

Los relatos biográficos de las personas entrevistadas relevan que no existe un único motivo para salir del lugar de origen. Al contrario, es posible reconocer que las motivaciones para emigrar de Chiloé refieren a factores familiares, económicos, educativos y por experimentar una aventura migratoria. Priman básicamente las dos primeras razones.

En el caso de las motivaciones familiares, es posible observar que son principalmente las mujeres quienes se desplazan por esta razón. Se encuentran causas tales como venir a buscar al marido, reunificación familiar, venir a casarse o "arrancar" de situaciones familiares complejas. Solo un caso corresponde a un hombre que migra para ver a su hermana licenciarse. Las personas entrevistadas cuentan que:

“Tendría unos 30 años cuando vine a Punta Arenas. Salí de Chiloé, porque mi marido estaba acá y no llegaba. Yo tenía 25 años cuando mi marido se vino a trabajar y como no había vuelto a Chiloé lo vine a buscar" (Mujer, 77 años, migró en 1969).

"Terminó el cuarto medio mi hermana acá en Punta Arenas, y nosotros vinimos a la licenciatura. Ella vino más jovencita a estudiar, y yo finalmente me quedé acá. Yo no lo pensé mucho y listo, me quedé. Por un mes, dos meses, tres meses y ya llevo más de 30 años" (Hombre, 51 años, migró en 1986).

A diferencia de la causa anterior, en las migraciones por motivaciones económicas prevalecen los hombres, quienes migran a Magallanes para buscar trabajo, porque se encontraban desempleados en Chiloé o sufren alguna crisis económica-familiar.

"En Chiloé no había posibilidad de trabajo, no había nada, si toda la gente migraba a Punta Arenas o a Argentina. La mayoría de la gente de mi edad se fue y no regresó. Yo me vine solo a Punta Arenas para buscar trabajo, por mejores condiciones de vida" (Hombre, 54 años, migró en 1982).

“Vine el '98. Ese año estaba el boom del mundial de Francia y en Chiloé estaba el boom de las salmoneras. Pero hubo una crisis con el tema del dumping, que es una estrategia comercial internacional, consiste en dañar el producto de una empresa y así me quedé sin trabajo" (Hombre, 44 años, migró en 1998). 
A diferencia de las otras causas, las motivaciones educacionales son las más recientes dentro del discurso, siendo una razón indiscriminada tanto en el hombre como en la mujer. La continuidad de estudios motiva a las nuevas generaciones isleñas a emigrar de Chiloé. Según relatan, Punta Arenas es una alternativa, porque existen redes familiares que los pueden acoger y, por ende, "alivianar" el proceso adaptativo en la ciudad y reducir los costos económicos.

"El 2009 me vine a estudiar. Postulé en primera opción a Historia en la Universidad de Magallanes. Fue a la única universidad que postulé, porque en Punta Arenas estaba mi tía, la hermana de mi mamá. Yo ya conocía la ciudad, porque en el verano de 2007 vinimos de viaje a visitar a mi tía" (Mujer, 26 años, migró en 2009).

"El 26 de febrero me vine a Punta Arenas. Tenía 19 años. Vine a Punta Arenas, porque como mi mamá era de Natales tenía una tía que vivía acá. Vine a estudiar (...) Di la PSU, saqué como 580 puntos ponderados y me vine a estudiar Pedagogía en Inglés en la UMAG" (Hombre, 32 años, migró en 2005).

Llegada y radicación en Punta Arenas:

Redes migratorias, desplazamiento territorial y trabajo

Para la mayoría de las personas entrevistadas, Punta Arenas representa el primer lugar de desplazamiento fuera del archipiélago. Sin embargo, lo anterior no necesariamente implicó una radicación inmediata y definitiva en la ciudad; al contrario, quienes migraron de Chiloé por razones familiares y económicas se desplazaron por la región de Magallanes y la Patagonia argentina en función de las oportunidades laborales que se iban presentando y gracias a las redes de apoyo que existían en los distintos lugares. En la región, se desplazan a Puerto Natales o Tierra del Fuego a trabajar en las estancias ganaderas o en la Empresa Nacional del Petróleo. En Argentina, llegan a Río Turbio, Río Gallegos, Río Grande o a Puerto Santa Cruz. Esos viajes no fueron definitivos, ya que estaban condicionados por las posibilidades de trabajo y/o conflictos fronterizos.

"Mi esposo me mandó a buscar para irme a Argentina. Me fui con mis hijas a Gobernador Gregores, Santa Cruz, en el '74 o '75. Estuve 3 años, allá nació mi otro hijo. Cuando se armó la revuelta Chile-Argentina, dije: "Me voy a mi país. Allá voy a estar mejor". Tuvimos que venirnos [devuelta a Punta Arenas]" (Mujer, 69 años, migró en 1968).

"Llegué donde una prima que vivía en la población Calixto. Estuve más de un mes, no pude conseguir trabajo. Después vino un primo de Gallegos y me dijo: "Vamos para allá, está sobrando el trabajo; yo te pago los pasajes". Así que me fui a Gallegos" (Hombre, 70 años, migró en 1967). 
Las personas que migran a Punta Arenas cuentan con redes de apoyo en la ciudad, siendo un factor clave y condicionante del desplazamiento. En el caso de las personas entrevistadas, todas refieren contar con algún conocido, generalmente dentro del núcleo doméstico eran los hermanos/as quienes ya se encontraban residiendo y motivaron la venida del resto de los integrantes del grupo. En aquellas situaciones donde las personas del núcleo no han migrado, existen integrantes de la familia extensa quienes actúan como red y asumen el rol de contener al nuevo inmigrante en su llegada al lugar de destino.

"En barco vine, en el Villarica. Yo tenía un tío, pero no lo conocía, sabía la dirección, dónde estaba y coloqué telegrama en Castro diciéndole que venía a Punta Arenas. Mi tío me había ido a encontrar. Ahí llegué a su casa” (Hombre, 79 años, migró en 1960).

"Nosotros somos diez hermanos, los mayores ya estaban por estos lados, por Argentina y por Punta Arenas. Como teníamos la mayoría de los hermanos acá, los mayores dijeron 'vénganse para acá, porque allá el campo tampoco lo vamos a ir a trabajar" (Mujer, 63 años, migró en 1977).

En la decisión de radicarse, de asentarse definitivamente en la ciudad tanto las redes migratorias como la estructura socio-económica del lugar de origen y llegada condicionan la permanencia. Hay personas que relatan que venían a estar un breve tiempo y llevan más de medio siglo en Magallanes. Otros inician nuevos procesos de reunificación familiar donde ya no es exclusivamente el padre quien migra primero para que luego, y una vez establecido, viaje la mujer e hijos/as; también es posible encontrar casos donde es el/la progenitora/a quien sale de Chiloé a estudiar o trabajar y luego trae a sus padres y/o hermanos/as.

"La misión era volver a Chiloé y ayudar a la familia. No volví, pero traje a mi gente después. Ellos pasaron por la crisis del virus ISA (...) Terminé el 2010 de estudiar, sin pega, les dije 'vénganse no más', y se vinieron a un mundo totalmente distinto, sobre todo para mi papá, él no había vivido en otra parte que no sea Chiloé” (Hombre, 32 años, migró en 2005).

Además de la influencia de la red migratoria, en los discursos de las personas entrevistadas se esboza un conocimiento de la región y de la Patagonia argentina previo a sus migraciones, porque el resto de los integrantes de su familia nuclear, extensa o la propia comunidad tenían una vinculación con la zona de llegada. Generalmente, existía como referente de migración la imagen masculina. Él era quien viajaba a la Patagonia para trabajar en las actividades vinculadas a la estancia, principalmente para la temporada de esquila. 
"Cuando tenía 16 años me fui a Argentina con mi papá. Mi papá fue esquilador. Fue mi primer trabajo porque en ese tiempo en Chiloé no había fuente laboral, no es como ahora que hay salmoneras, pesqueras, cultivos de choros, varias otras actividades" (Hombre, 53 años, migró en 1982).

"Yo tendría unos 7 años cuando mi papá viajaba. Venía a la Argentina, a trabajar en la temporada de esquila y trabajó en una estancia que fue una de la más grande de Argentina, Estancia Despedida. Venía a estar toda la temporada de verano y en el invierno volvía a Chiloé. Siempre lo veía viajar solo, después trajo a su hijo mayor" (Mujer, 70 años, migró en 1966).

"Nos vinimos en el barco Villarica con una pariente que trabajaba acá. Yo tenía parentela que venía y llegaba de vuelta, entonces siempre se escuchaban comentarios de Punta Arenas, porque toda la gente se venía a trabajar, a hacer la temporada de esquila o al frigorífico" (Mujer, 79 años, migró en 1957).

Pero también existen casos particulares donde el referente migratorio y el conocimiento previo de la región se explica, porque alguna de las líneas de parentesco era originaria de Magallanes, es decir, existió una migración inversa a la estudiada, un desplazamiento desde Magallanes a Chiloé.

"Somos todos chilotes. Bueno, mi mamá es de Puerto Natales, vivió en Río Grande $y$ en Gallegos. A los 23 años se va a Chiloé. Ella estaba metida en un tema religioso: evangélica. Y migra el año '68 a Chiloé con otra persona que iba como de pastora. En Chiloé conoció a mi papá" (Hombre, 32 años, migró en 2005).

"Ya conocía la ciudad, porque en el verano del 2007 vinimos de viaje a visitar a mi tía. Además, mi papá siempre me hablaba de Punta Arenas, porque su infancia la vivió acá. La familia de mi papá es de Magallanes” (Mujer, 26 años, migró en 2009).

En los relatos sobre migraciones chilotas a Punta Arenas se observa que todas significaron una migración rural-urbana. Asociado a lo anterior, se desprende que la radicación en la ciudad significó cambiar su condición y relación con el trabajo productivo, de campesinos y campesinas a cuenta propia, se transforman en personas asalariadas dependientes y se insertan en un mercado laboral asociado a actividades de la construcción, de la ganadería en las estancias y frigoríficos, de la empresa petrolera, empresas acuícolas, asesoras de hogar, damas de compañía, trabajadoras de la educación, mineros del carbón, entre otros rubros. Todas las personas, incluso aquellas que llegaron a estudiar, se vincularon con el mercado laboral de la región.

"Los primeros meses trabajé de ayudante de camionero. Trabajaba repartiendo carbón a distintas partes. Pasábamos a cargar a la mina Pecket, ir a las estancias a entregar y también distribuir a la gente en Punta Arenas porque la ciudad se mantenía 
con puro carbón y algo de gas (...) A fines del '58 me contacté con gente de la estancia Pecket, de la Sociedad Ganadera Sara Braun, y me fui a trabajar a esa estancia, a 40 kilómetros de Punta Arenas. Soy operador de máquina pesada, ahí trabajé varios años" (Hombre, 77 años, migró en 1957).

“Trabajé dos años como dama de compañía de la señora Mayo, esposa del señor Maclean, que tiene la Estancia El Trébol. Me conoció la señora y me dijo: "Tú eres indicada para que estés junto a mí”. Conversábamos, nos sentábamos, mirábamos libros. Ese era mi trabajo" (Mujer, 70 años, migró en 1966).

“Acá estudié y trabajé. Si trabajé toda una vida, como no iba a volver a trabajar. Fui al muelle Prat, hablé con los estibadores, les dije que era estudiante, que venía de Chiloé, que quería trabajar en la faena y me dieron pega. Trabajaba estibando mercadería. Después trabajé en el Líder de auxiliar de cocina, ahí me daban colación, me daban almuerzo, también tenía la beca de la UMAG; como buen chilote me aseguraba con la comida" (Hombre, 32 años, migró en 2005).

Dentro de las trayectorias laborales, solo cuatro personas continúan reproduciendo su condición de trabajo desarrollada en Chiloé, un zapatero que en Punta Arenas, además de dedicarse a otras actividades, se convierte en zapatero apatronado y luego se independiza con su propio taller de reparación de calzado; una mujer del área de la educación que en la ciudad se desempeña en el mismo rubro; otra mujer que en ambos lugares se dedicó a ser empleada doméstica; y un hombre que trabajaba en una empresa acuícola en Chiloé y en Punta Arenas se inserta en la misma área.

“De los 14 años, al salir de la escuela, empecé a trabajar en un taller, le dije a mi mamá que quería trabajar en la zapatería con la idea tonta para hacerle zapatos a mi mamá (...) En Punta Arenas volví a trabajar en zapatería; trabajé con patrón en la Reparadora de Calzado Quilpué durante cinco años; luego me independice. Yo soy obrero del cuero y del calzado; zapatelógrafo soy. En zapatería toda mi vida” (Hombre, 79 años, migró en 1960).

"Nosotros no nos vinimos [de Chiloé] por trabajo, porque yo incluso ya había trabajado un tiempo en una escuela, haciendo un reemplazo como técnica en párvulos. Eso lo estudié en el Politécnico de Castro que funcionaba en Ancud donde estuve internada. [En Punta Arenas] Verdaderamente había buen trabajo, encontré trabajo inmediatamente, me fueron a buscar a la casa más bien dicho. Trabajé 39 años como técnico en educación parvularia en la JUNJI" (Mujer, 63 años, migró en 1977).

El resto de las personas se incorporaron en nuevos mercados y desarrollan/aprenden nuevos oficios. Frente a lo laboral, los/as migrantes isleños constituyen evidentemente una importante fuerza de trabajo dentro de la región. 
Choque cultural en Punta Arenas: Esbozos de una discriminación

Cuando las personas entrevistadas hablan del proceso migratorio y de su inserción en la vida social y económica de Punta Arenas existe un tema que emerge de lo más profundo de la vivencia, a través de la palabra como expresión de verdad o desde el silencio como expresión de olvido o negación. Hablar de migración es hablar del choque cultural, de las identidades en disputa y de la discriminación, la cual se puede manifestar en acciones de violencia física y/o simbólica.

Las personas chilotas que se han sentido discriminadas han vivenciado un trato diferente por el motivo de haber nacido en un determinado lugar y cargar con el territorio como un elemento de identidad y también de clase social que define a la persona. Para algunas, incluso nominarlas como chilotas/es constituye un acto de discriminación.

En los relatos de vida fueron hombres quienes relevaron de forma directa el tema. No así las mujeres, quienes hablan de la discriminación vivida por otros. Sin embargo, ese otro -sujeto de discriminación- es un alguien que carga con su misma categoría social: ser una persona de Chiloé, un inmigrante del norte del país.

“(...) acá a los chilotes parece que los desprecian mucho (...) se ríen de los chilotes. Pero donde se plantan los chilotes, no hay ninguno que lo saque. Porque los chilotes son trabajadores; (...) se crecen pero a puro trabajo. Yo lo he oído decir aquí, oído menospreciar a los chilotes (...)" (Mujer, 77 años, migró en 1969).

Los hombres entrevistados que hablaron de discriminación basada en su propia experiencia no se limitan a una época específica, por el contrario, son testimonios que representan a migrantes que llegaron a Punta Arenas en distintas décadas, con distintas edades, quienes se insertaron en espacios sociales y laborales diferentes. La discriminación fue sentida por quien siendo niño ingresó a la escuela y por hombres en edad económicamente activa, que en su llegada se incorporaron a mercados de trabajo en el área de la construcción y en la acuicultura. Estas personas relatan que:

"El chilote incluso es mal mirado, es despreciado, qué chilote tal por cual. A mí me chiloteó un capataz cuando trabajé en la construcción (...) y eso no lo voy a aguantar nunca, si el chilote es trabajador, si Magallanes aquí un poco se ha levantado por puros chilotes también" (Hombre, 77 años, migró en 1957).

"Cuando me inicié en la piscicultura me chiloteaban. Me agarré con uno de acá porque me molesta y me duele que una persona me chilotee, siendo que su abuelo era chilote. Es lo mismo que mi hija chilotee a otro, siendo que yo soy chilote" (Hombre, 44 años, migró en 1998). 
"[Me sentí discriminado] por ser chilote, aparte que teníamos otro lenguaje. Por ser, los niños, era todo distinto. Éramos la burla, entonces, claro, yo tuve igual vergüenza de ser chilote en un momento (...) igual costó mucho al comienzo asumir que eres chilote, decir que eres chilote, muy, no sé, como de burla" (Hombre, 30 años, migró en 1996).

\section{La identidad sentida: Ser chilote en Magallanes}

La identidad permite una construcción de sentido y pertenencia a un grupo social específico, a través del reconocimiento de ciertos elementos que son considerados como propios y que, por tanto, definen a un colectivo y lo diferencian de un otro. En ese sentido, la identidad supone una adscripción por parte las personas que comparten ciertos rasgos culturales, siendo una representación colectiva que refuerza las diferencias y que actúa como una frontera cultural en sí misma.

En el caso de las personas migrantes de Chiloé la identidad y el reconocimiento de la misma supone también un proceso de construcción dinámica en el tiempo. Al traspasar las fronteras geográficas la identidad se ve enfrentada y confrontada de forma más evidente con quienes representan a los otros, lo cual puede generar distintas respuestas según como sea percibida y vivida la incorporación social de la persona migrante en el lugar de llegada. El proceso es complejo ya que puede involucrar una negación de la identidad al experimentar vivencias discriminatorias como también un reconocimiento que tienda a fortalecer y apropiar aún más la identidad propia. Lo anterior incluso puede ser un continuo de un mismo proceso precisamente por el carácter dinámico de la identidad como constructo cultural.

En el caso de las personas chilotas existe un reconocimiento de su identidad como isleños, estableciendo distintas características que los definen y los diferencian del resto de la población asentada en la ciudad magallánica. Según relatan, una cualidad genérica es ser personas de trabajo, de esfuerzo, de buena voluntad, humildes, dispuestas a colaborar y poseedores de una cultura particular que se expresa en la gastronomía, en sus historias, en la religión, en la arquitectura y en el folclore.

"Chiloé me encanta porque de aquellos años, aunque todavía perdura, es una gente noble, muy sincera y humilde, la humildad es característico de Chiloé, la unión de vecinos, (...) aunque se ha perdido, pero eso es lo más representativo del chilote, ser humilde" (Hombre, 79 años, migró en 1960).

"El chilote es trabajador, la mayoría es gente muy honrada, honesta (...) donde hay un chilote, es una buena persona. Aunque para mí, el chilote yo creo que no destiñe; donde quiera que esté el chilote va a ponerse las pilas" (Mujer, 69 años, migró en 1968). 
"Yo me siento orgulloso de ser chilote. Porqué ¿Qué lugar de Chile tiene una identidad propia, en la religión, en la arquitectura, en la gastronomía, en el folclore, y en varias cosas más? La mitología, las leyendas, y son propias de Chiloé. (...) Te das cuenta de muchas cosas cuando no estás en tu tierra" (Hombre, 51 años, migró en 1986).

"El tema de la disposición por ejemplo o el trato, porque se nota mucho una persona que es chilota a uno persona que no lo es; en el sentido del recibimiento por ejemplo (...) yo creo que en el trato, el chilote como en el trato, disposición, siempre te va a querer ayudar, si le pides algo, como que va a tratar de hacer lo posible” (Mujer, 26 años, migró en 2009).

\section{Chiloé en Punta Arenas: rupturas y continuidades culturales}

Toda migración implica reproducir la vida en un nuevo lugar de destino, lo cual supone una transformación en las formas de vida de un grupo específico, generándose un quiebre de ciertas prácticas y, al mismo tiempo, una continuidad de algunas de ellas. Transformación que impacta en la construcción de memoria del grupo, ya que supone un juego contradictorio entre lo que se dice recordar y lo que no, y entre lo que se puede recordar desde el discurso y práctica y aquello que es silenciado y olvidado en el nuevo territorio de residencia.

Un cambio evidente para las personas migrantes de Chiloé ha sido modificar la relación con el espacio geográfico, ya que el traslado de un mundo rural a un mundo urbano supone transformar ciertas prácticas cotidianas que influyen en un conjunto de otras acciones. Por ejemplo, algunas personas mencionan que en la ciudad de Punta Arenas ya no podían criar cerdos o "chanchos", porque en sus nuevas residencias no contaban con el espacio físico para la crianza de animales lo cual implica, a su vez, modificar prácticas alimenticias, simbólicas y sociales. Para la gente de Chiloé, engordar un cerdo supone contar con una fuente clave de alimentación que no solo está pensada para la supervivencia del núcleo doméstico sino que involucra la posibilidad de preparar e intercambiar un plato de comida con vecinos y familiares. El lloco, por ejemplo, que es un plato en base a cerdo ahumado, sopaipillas, milcao y roscas, simboliza un acto de donación en la tríada dar, recibir y devolver, lo cual posibilita el fortalecimiento de los lazos sociales dentro de una comunidad.

"A una persona le toca un tiempo, cuando tiene sus chanchos para faenarlos, y todas las personas que reciben el lloco le devuelven a esa persona. Acá no se puede hacer el lloco, antes se podía tener chancho, ahora no, y generalmente se hace con un chancho que uno crece en la casa" (Mujer, 63 años, migró en 1977).

Sin embargo, reproducir la vida en otro lugar distinto al de origen supone por parte de la persona migrante elaborar estrategias que posibiliten la continuidad de ciertas 
prácticas cotidianas. Algunas, a pesar de las restricciones y del espacio, encontraron la manera de realizar ciertas actividades asociadas a su Chiloé rural, incluso las personas que migraron en las décadas del 50 y 60 a Punta Arenas criaron animales en sus propios patios. Según se observa, en el plano doméstico han sido principalmente las mujeres quienes han contribuido a la perpetuación de prácticas fundamentalmente culinarias y agrícolas.

“Acá en Punta Arenas nosotros siempre hemos sembrado, porque antes arrendábamos un terreno y ahí íbamos a sembrar. Y sembrábamos bastante, hasta vendíamos. Lo hacíamos igual que en Chiloé, con la luna caída; en la caída, empezábamos a sembrar y siempre en octubre” (Mujer, 88 años, migró en 1949).

"Cuando el barco pasaba a Castro traía [a Punta Arenas] bolsas de manzana, nalcas, chupones, papas, traía un montón de cosas. Entonces (...) hacíamos milcao, prietas, tortilla de rescoldo, empanadas de manzana (...) Nunca perdimos nuestra costumbre de hacer esas cosas” (Mujer, 79 años, migró en 1957).

Históricamente, Chiloé y Punta Arenas han estado estrechamente vinculados, existiendo un importante flujo no solo de personas sino también de productos, algunos se adquieren a través de la comercialización y otros se traspasan entre los mismos parientes o coterráneos que viajaban desde el archipiélago a trabajar temporalmente en la Patagonia, permitiendo la reproducción de hábitos alimenticios característicos de la vida doméstica en Chiloé.

“Cuandolos parientes se venían a trabajar aprovechábamos: "Ilévame chicharrones, llévame un pedazo de chancho, llévame harina tostada”. De Chiloé también traían el luche y el cochayuyo para vender. Venían en fardos grandes, entonces igual se compraba en el negocio para hacer la cazuela de luche o de cochayuyo" (Mujer, 79 años, migró en 1957).

“Acá compraba los productos a los pescadores o compraba a la gente que viajaba a Chiloé. [El barco Navarino] Cuando llegaba hacía llegar cholgas secas, navajuelas, sierras, ahumadas y frescas, nalcas de Chiloé. Navarino en ese tiempo traía de todo a Punta Arenas" (Mujer, 79 años, migró en 1969).

La gastronomía está revestida de una dimensión cultural y junto con el desplazamiento de personas isleñas existe una migración gastronómica, de productos y prácticas culinarias asociadas con el sabor y el comer a lo chilote. La preparación de alimentos en la población migrante actúa como un recurso de supervivencia material e inmaterial en el lugar de destino y también en la construcción de identidad, de un "nosotros" localizados en un espacio determinado. La comida chilota tiene particularidades 
propias del territorio de origen y de la vida social y productiva de Chiloé, en ese aspecto contiene una parte de la identidad cultural asociada al tipo de alimento, a la forma de preparación, a las distintas funciones que se deben cumplir en el proceso y al sentido social y simbólico que tienen dentro de la comunidad. En el lugar de destino, las prácticas culinarias son re-apropiadas para actuar precisamente como un recurso identitario que permite aglutinar a las personas migrantes y crear comunidad. En la ciudad de Punta Arenas, la comida evoca constantemente a Chiloé, siendo un elemento tangible de su cultura. En la migración existe un desplazamiento de la práctica culinaria, en ese sentido una continuidad cultural, pero el espacio de expresión y la función gastronómica rompen con los precedentes de origen. En Punta Arenas existe un desplazamiento de la gastronomía doméstica a una gastronomía del comercio, emergiendo distintos negocios que venden productos, alimentos y preparaciones chilotas como el milcao, la tortilla de papa, la churrasca, las roscas, la chochoca, el curanto, la chicha de manzana, empanadas de manzanas, entre otras.

Además de la alimentación -situada inicialmente en el plano doméstico de las prácticas y luego trasladada al plano público del comercio- el mundo simbólico de Chiloé se comienza también a revitalizar en Punta Arenas y cobra significancia dentro de la vida urbana de la ciudad magallánica varias décadas después de transcurrido el asentamiento de la población isleña. Se observa que la conformación de organización social en la comunidad chilota juega un papel clave para re-significar la cultura, a través de celebraciones rituales y religiosas como es la Noche de San Juan o la Novena y Procesión de Jesús Nazareno de Caguach.

En esta ciudad magallánica, que podemos denominarla como el otro lugar, la reproducción de la vida social y cultural del archipiélago es una manera de acercamiento y evocación a la tierra de origen que no se realiza de manera idéntica a lo vivido en Chiloé, es un intento de perpetuar prácticas no desde el sentido purista de la cultura sino como una estrategia flexible que adapta lo propio con lo ajeno, creando una apropiación/ revitalización de referentes y prácticas en el lugar de destino sin perder el origen. Es una manera de expresar un sentimiento de filiación al origen. Por ejemplo, se observa que la Noche de San Juan en Punta Arenas adquiere ribetes distintos a las vivencias relatadas en el archipiélago. En Chiloé, se realiza el tradicional carneo de chancho, el reitimiento. El día 22 se carnea el animal, el día 23 se empieza a cocinar la carne y otras preparaciones. Ese día en la noche llegan los invitados para comer y esperar la noche de San Juan. Para esa celebración popular también se preparaba especialmente el chopón o tropón, una bola de chuño de papa que se cocina a la brasas del fogón y se come por capas. Dicen que a las 12 de la noche, la gente sale de sus casas a gritar arriba de un cerro. La gente isleña inventaba una historia y llamaban a San Juan para realizar alguna petición. En cambio, en Punta Arenas las modificaciones en torno a la festividad son visibles porque, en primer lugar, no es una celebración realizada en el seno de un núcleo doméstico 
sino más bien una fecha conmemorativa que aglutina a un conjunto de personas en un espacio público que suele ser el lugar donde funcionan las organizaciones chilotas, por ejemplo, en la sede del Centro Ancuditano o en el Centro Hijos de Chiloé, esta última con una orientación más masiva donde se congregan personas provenientes de Chiloé, como también descendientes chilotes y magallánicos. En esta celebración se replican rituales y degustación gastronómica. Asimismo, se despliega una performance donde se muestra el folclore no solo del archipiélago sino también de la Patagonia, por ejemplo, el chamamé. En el Centro Hijos de Chiloé cuentan que las roscas chonchinas y la mistela, conocida como licor de oro, las mandan a buscar directamente a Chiloé. Replican ciertas pruebas como la del gallo y las tres niñas solteras, y la de las tres papas.

La Novena y Procesión de Jesús Nazareno de Caguach es otra manifestación que refleja los cambios y continuidades; un juego característico de la cultura y de su dinamismo. En la caso de esta celebración religiosa se observa cómo un memoria subterránea y silenciosa se fue paulatinamente posicionando dentro de la vida urbana de Punta Arenas y de su calendario regional. La devoción al Nazareno se manifiesta colectivamente desde 1981. En sus inicios se realizaba en el plano íntimo de una vivienda de la población 18 de septiembre. Al principio se juntaban en el domicilio de la familia Unquén, migrantes de la isla Caguach. De estas reuniones surge la comunidad Jesús Nazareno de Caguach. Se dice que cuando iniciaron esta devoción solo tenían una foto en blanco y negro del Nazareno que mandaron a pintar. Esa imagen a color fue la primera forma de adoración y de re-significación del fervor religioso popular de Chiloé. Luego, en 1986 llega la imagen de madera, con su cara y mano enlozadas, y con su túnica morada que representa el color del dolor, del sufrimiento para la Iglesia Católica. Nazareno fue llevado a la iglesia de Fátima y ubicado en un rincón hasta el año 2001 cuando la comunidad materializa su sueño con la edificación del Santuario Jesús Nazareno y en donde cada último domingo de agosto realizan una masiva procesión por la ciudad de Punta Arenas que termina con la tradicional corrida de roscas. En Chiloé se celebra sagradamente cada 30 de agosto.

\section{Punta Arenas en el hoy: Presencia chilota en una ciudad magallánica}

Entender que la memoria social de un grupo migrante se encuentra arraigada más allá del discurso oral y testimonial de las personas que han vivenciado ese proceso demográfico, supone comprender que la presencia de Chiloé en Punta Arenas y en la vida urbana de la ciudad magallánica se encuentra en una variedad de elementos alusivos a la tierra de origen, a la cultura y a su identidad.

Si retomamos los planteamientos de Baer (2010) podemos ver en concreto cómo en la ciudad de Punta Arenas se han levantado distintos "espacios de memoria", templos, monumentos, conmemoraciones, testigos y testimonios que dan cuenta de la influencia chilota en la historia de la región y en la vida urbana. 
El siguiente cuadro (Tabla $1^{5}$ ) enuncia algunos referentes de la impronta cultural de Chiloé en Punta Arenas, dando cuenta de una memoria desbordada por el espacio público de la ciudad de destino y, al mismo tiempo, anclada al territorio de origen. Estos diferentes puntos de referencias actúan como indicadores empíricos de la memoria colectiva del pueblo chilote en Punta Arenas.

En cuanto a la propuesta de georreferenciación elaborada en el marco de la investigación fue posible visibilizar Chiloé en esos distintos elementos materiales e inmateriales desplegados en la ciudad de Punta Arenas. Al ser puntos de referencia dan cuenta cómo la memoria colectiva de las personas migrantes de Chiloé en Punta Arenas ha sido construida, deconstruida y reconstituida en otro lugar.

La imagen presentada a continuación (Figura 1), muestra el plano urbano de Punta Arenas y la ubicación espacial de algunos de los referentes enunciados en la Tabla 1, siendo posible observar que la presencia de Chiloé está concentrada mayoritariamente en la zona centro-sur de la ciudad, con una fuerte presencia de aquellos referentes empíricos del ámbito económico, social y urbanístico ${ }^{6}$.

En cada uno de esos elementos distribuidos espacialmente es donde la memoria colectiva de migrantes de Chiloé se hace presente, expresándose de forma latente y manifiesta en ese conjunto de elementos. Cabe señalar que los referentes empíricos de la memoria son dinámicos, algunos se han ido perpetuando a lo largo del tiempo, otros han emergido como símbolo de reconocimiento o estrategia material, otros surgen en momentos específicos para luego desaparecer, y otros se han ido "magallanizando" y "sincretizando" con las lógicas regionales.

Decíamos que las memorias de este grupo migrante en Magallanes han sido históricamente memorias subterráneas que han proseguido su trabajo de empoderamiento desde el silencio y desde la periferia hasta posicionarse dentro de la historia y de la construcción de la memoria regional. Identificar algunos referentes empíricos muestra que las memorias de los/las migrantes de Chiloé salen a "flote" en la ciudad de Punta Arenas y la permean constantemente.

La Tabla 1 ha sido elaborada principalmente a partir de la información recopilada durante la investigación de terreno realizada el año 2017. Para efectos de este artículo, existen algunos ajustes al trabajo. En primer lugar, señalar que dicha información ha sido actualizada con algunos nuevos referentes que no habían sido identificados, registrados ni georreferenciados previamente. En segundo lugar, mencionar que los nombres de las dimensiones han sido levemente modificados para evitar redundancias (por ejemplo, antes se denominaba arquitectónica-histórica a la dimensión arquitectónica; organizativa-social a la dimensión organizativa; simbólica-cultural a la dimensión simbólica; simbólica-social a la dimensión social; y económica-social a la dimensión económica).

Cabe comentar, a su vez, que algunos de los referentes que son mencionados en la dimensión simbólica no se encuentran georreferenciados porque no tienen una ubicación concreta en el espacio urbano, tal es el caso de la obra de teatro o de personajes e hitos históricos como Juan Agustín Yañez, Felicia Barría o el Feriado del día 21 de septiembre que conmemora la toma de posesión del Estrecho de Magallanes. En este sentido, es importante reflexionar que la Tabla 1 no tiene por qué ser una propuesta metodológica inmodificable en el tiempo; al contrario, reflexionar sobre las dinámicas, los alcances o multi-dimensiones de cada referente puede permitir incluso proponer una nueva categoría para aquellos elementos nogeorreferenciables, por ejemplo, incorporar una dimensión histórica que aglutine aquellos referentes que, aunque no tengan necesariamente una distribución concreta en el espacio, forman parte de la memoria del pueblo chilote en Punta Arenas.

6 La georreferenciación ha sido realizada con la colaboración del arquitecto Nicolás Recabarren Traub. 
Tabla 1. Algunos referentes de Chiloé en Punta Arenas.

\begin{tabular}{|c|c|c|}
\hline DIMENSIÓN & COMPONENTE & REFERENTE EMPÍRICO \\
\hline Arquitectónica & $\begin{array}{l}\text { Casas, iglesias y estructuras físicas que } \\
\text { reproducen fachadas representativas de } \\
\text { Chiloé. }\end{array}$ & $\begin{array}{l}\text {-Iglesia Santuario Jesús Nazareno } \\
\text {-Necrópolis chilota, Cementerio Municipal de Punta Arenas } \\
\text {-Casa revestida con tejuelas de madera } \\
\text {-Restaurant El Lloco }\end{array}$ \\
\hline Organizativa & $\begin{array}{l}\text { Grupo organizado de personas que } \\
\text { conforman asociaciones. Tienen como } \\
\text { sello representativo la identidad chilota. }\end{array}$ & $\begin{array}{l}\text {-Centro Ancuditano } \\
\text {-Centro Hijos de Chiloé } \\
\text {-Agrupación Conjuntos Chilotes ACOCHI } \\
\text {-Comunidad Santuario Jesús de Nazareno }\end{array}$ \\
\hline Urbanística & $\begin{array}{l}\text { Calles, Toponimia, Monumentos, } \\
\text { Iglesias; Poblaciones relacionadas con } \\
\text { Chiloé. }\end{array}$ & $\begin{array}{l}\text {-Monumento a la Goleta Ancud } \\
\text {-Monumento al Ovejero } \\
\text {-Barco réplica Goleta Ancud, Museo de Sitio Nao Victoria } \\
\text {-Casa de Francisco Coloane } \\
\text {-Población } 18 \text { de septiembre } \\
\text {-Jardín Infantil Intercultural Archipiélago de Chiloé } \\
\text {-Población Archipiélago de Chiloé } \\
\text {-Población Río de la Mano } \\
\text {-Puente Chiloé } \\
\text {-Calles: Abel Oyarzún, Chiloé, Chilote Díaz, Los Mansilla, Los Ulloa, Los } \\
\text { Coliboro, Ancud, Castro, Chonchi, Dalcahue, Canal de Chacao, Linao, } \\
\text { Huillinco, Lliuco, Los Uribe, Los Ulloa, Los Cárdenas, Los Gallardo, Los } \\
\text { Huichipán, Los Hueicha. } \\
\text { Iglesias: Santuario Jesús Nazareno, Fátima, Cura de Ars, San José El Carpintero, } \\
\text { San Fransico de Asis. }\end{array}$ \\
\hline Simbólica & $\begin{array}{l}\text { Imágenes, símbolos, historias y/o } \\
\text { leyendas alusivas a Chiloé. }\end{array}$ & $\begin{array}{l}\text {-Mural con imagen de Jesús Nazareno en portón de una vivienda } \\
\text {-Cartel con imagen de iglesia de Colo y del Puerto de Quemchi en publicidad de } \\
\text { Hostal Doña Anita } \\
\text {-Mural con imagen de Chiloé en Centro Hijos de Chiloé } \\
\text {-Figuras e imágenes del Nazareno en tumbas del cementerio } \\
\text {-Leyenda de la Población Río de la Mano } \\
\text {-Feriado legal } 21 \text { de septiembre. Conmemoración de la toma de posesión del } \\
\text { Estrecho de Magallanes } \\
\text {-Obra de teatro Mechuñe Negro } \\
\text {-Juan Agustín Yañez, migrante chilote, miembro de la Junta de Alcaldes y primer } \\
\text { alcalde chilote 1929-1935 (Moreno, s.f.) } \\
\text {-Felicia Barría Vera, migrante chilota y primera mujer en presidir la alcaldía de } \\
\text { Punta Arenas 1950-1953 }\end{array}$ \\
\hline Social & $\begin{array}{l}\text { Conjunto de prácticas referidas } \\
\text { principalmente a festividades religiosas } \\
\text { o comunitarias características de Chiloé. }\end{array}$ & $\begin{array}{l}\text {-Festival Costumbrista de Chiloé } \\
\text {-Celebración de la Noche de San Juan } \\
\text {-Ceremonia Toma de posesión del Estrecho de Magallanes } \\
\text {-Novena y Procesión de Jesús Nazareno de Caguach } \\
\text {-Fiesta religiosa de la Candelaria } \\
\text {-Fiesta religiosa de Fátima } \\
\text {-Fiesta religiosa de San Francisco } \\
\text {-Fiesta religiosa San Pedro Pescador } \\
\text {-Fiesta religiosa Novena del Carmen } \\
\text {-Reitimiento de chancho } \\
\text {-Encuentro de acordeonistas }\end{array}$ \\
\hline Económica & $\begin{array}{l}\text { Comercio, productos y/o negocios } \\
\text { vinculados tanto con la gastronomía } \\
\text { tradicional chilota como con nombres } \\
\text { referidos a Chiloé. }\end{array}$ & $\begin{array}{l}\text {-Restaurant El Mercado chilote } \\
\text {-Restaurant Donde Hueicha } \\
\text {-Restaurant Centro Hijos de Chiloé } \\
\text {-Restaurant El Lloco } \\
\text {-Bar El Chonchino } \\
\text {-Almacén El Quehuino } \\
\text {-Almacén La Pincoya } \\
\text {-Almacén La Económica } \\
\text {-Almacén Tenaún } \\
\text {-Almacén El Hornito } \\
\text {-Almacén Chacao } \\
\text {-Almacén La Goleta Ancud } \\
\text {-Almacén El Nuevo Castreño } \\
\text {-Pescadería San Pedro } \\
\text {-Pescadería El Caleuche } \\
\text {-Pescadería La esquina del Cholo } \\
\text {-Transportes y Bodega de productos agrícolas de Chiloé San Andrés } \\
\text {-Night Club Rilán } \\
\text {-Funeraria Jesús Nazareno }\end{array}$ \\
\hline
\end{tabular}




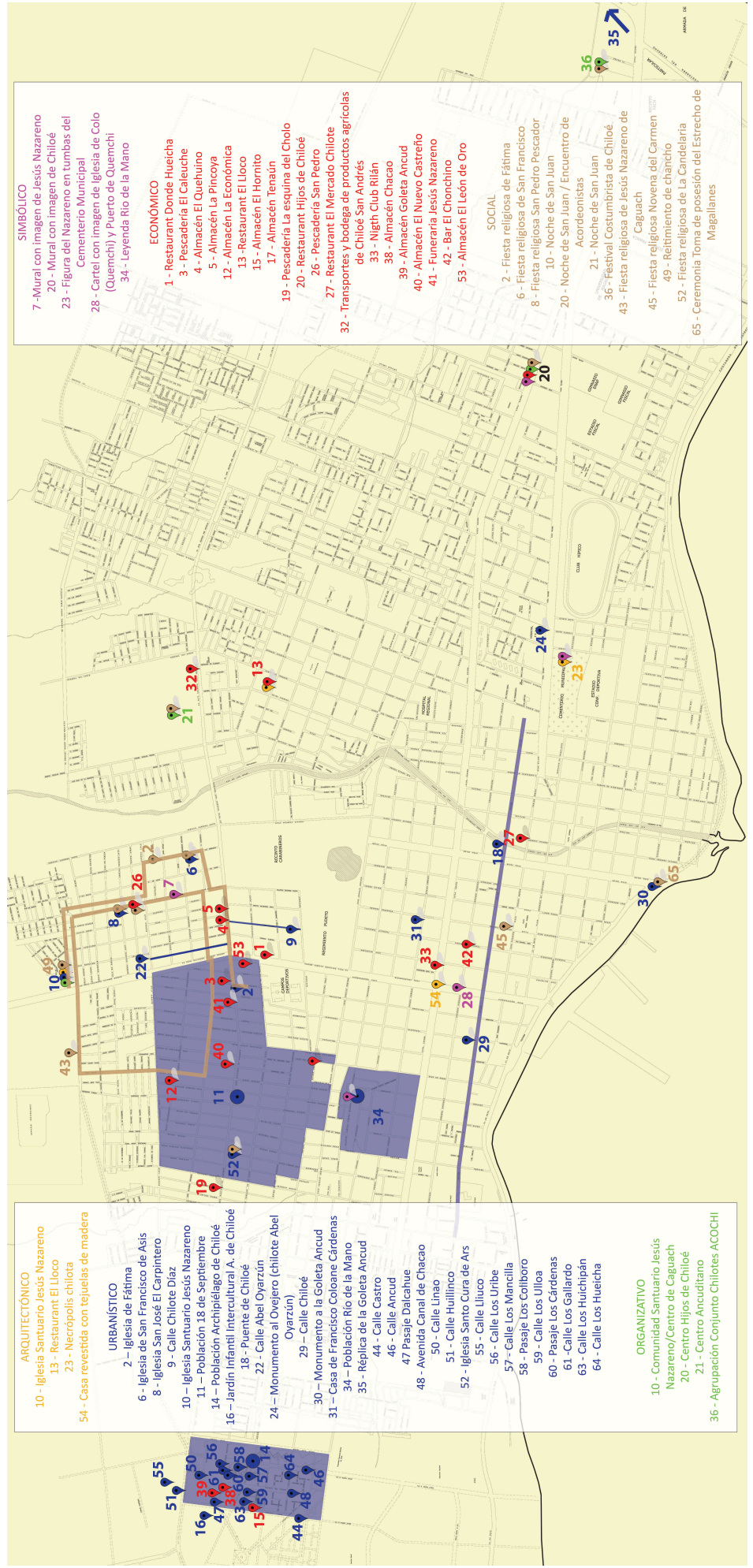

Figura 1. Georreferenciación de algunos referentes de Chiloé en Punta Arenas. Fuente: Fernández, M. y Riveros, K., 2017. 


\section{CONCLUSIONES}

Reconstruir el relato testimonial de distintas personas que han migrado desde Chiloé a Punta Arenas ha permitido desmitificar una categoría social instalada, la categoría del migrante chilote con características singulares y homogéneas. La memoria oral muestra que es una categoría diversa y compleja donde existen puntos en común, pero también divergencias. En ese sentido, resulta pertinente hablar de migrantes chilotes o de migraciones chilotas en sentido plural y como reconocimiento a las particularidades de los distintos desplazamientos, lógicamente particularidades que al estar insertas en contextos más amplios están, al mismo tiempo, atravesadas de factores generalizables. Lo significativo de este trabajo de investigación es que los distintos testimonios han permitido visualizar y visibilizar las migraciones chilotas como un fenómeno sociocultural que se ha mantenido en el tiempo y que, a pesar de responder a situaciones particulares de cada periodo histórico, es posible observar desplazamientos territoriales hacia Magallanes en las actuales generaciones de personas nacidas en Chiloé. En ese sentido, los relatos abordados construyen una manera de entender la migración como una dimensión sociocultural dinámica en el tiempo y aun presente.

En el campo de estudio de la antropología, donde las dimensiones sociales, culturales, económicas y/o simbólicas son el sustento para interpretar fenómenos asociados al poblamiento humano en un territorio, ya sea el de origen o de residencia, el relato testimonial de quien otorga el contenido de dichas dimensiones se transforma en una fuente primaria, porque fortalece y complementa información sobre acontecimientos, siendo esos recuerdos los que repercuten independiente del tiempo en que fueron vivenciados. Pero el relato oral en cuanto testigo y testimonio no es el único recurso de expresión de la memoria colectiva de un grupo social; por el contrario, la memoria se apoya y se manifiesta en un conjunto de referentes empíricos que se fueron lentamente levantando en el espacio urbano de la ciudad de Punta Arenas, desde palabras que evocan a Chiloé como en aquellas prácticas que se han ido posicionado incluso como referentes de la vida social en Magallanes, siendo transversales al resto de la población puntarenense.

La memoria social del pueblo chilote en Punta Arenas ha transitado desde una dimensión subterránea hasta disputar un espacio de reconocimiento en el ámbito público y en la conformación de la identidad regional magallánica. En el ámbito político-institucional incluso ha existido un intento por incorporar sus recuerdos como migrantes chilotes en la memoria colectiva de Magallanes, ejemplo de aquello ha sido la construcción del monumento a la goleta Ancud el año 2014 en plena avenida Costanera de la ciudad de Punta Arenas; o la conmemoración de la llegada de la goleta Ancud y la toma de posesión del estrecho del Estrecho de Magallanes el 21 de septiembre, estableciendo el año 2017 un feriado legal tanto en la región de Magallanes como en la Provincia de Chiloé; o la celebración del día del Patrimonio Regional del año 2017 donde existió un fuerte énfasis en el reconocimiento de 
los migrantes chilotes dentro de sus actividades culturales. Estas acciones representan los primeros pasos para seguir avanzado en el reconocimiento de la influencia y aporte cultural de las personas migrantes de Chiloé no solo en Punta Arenas sino también en la región de Magallanes.

\section{REFERENCIAS}

Auge, M. (2000). Los <<no lugares >>. Espacios del anonimato. Una antropología de la sobremodernidad. Barcelona: Editorial Gedisa

Baer, A. (2010). La memoria social. Breve guía para perplejos [en línea]. Disponible en: http:// www.politicasdelamemoria.org/2010/04/baer-alejandro-2010-la-memoria-socialbreve-guia-para-perplejos-7/

Candau, J. (2002). Antropología de la memoria. Buenos Aires: Nueva Visión.

Fernández, M., \& Riveros, K. (2017). Entre mares, pampas y vientos. Memorias de Chiloé en Punta Arenas. Santiago: Andros impresores.

Halbwachs, M. (2004). La memoria colectiva. Zaragoza: Prensas Universitaria de Zaragoza.

Lausic, S. (2005). Migraciones del archipiélago de la isla grande de Chiloé hacia la Patagonia (Chile-Argentina) y participación en el sindicalismo obrero, [en línea]. CEME - Centros de Estudios Miguel Henríquez - Archivo Chile. Disponible en: http://www.archivochile. com/Historia_de_Chile/otros_artic/HCHotrosart0011.pdf

Mancilla, L. (2012). Los chilotes de la Patagonia Rebelde. La historia de los emigrantes chilotes fusilados en las estancias de Santa Cruz, Argentina, durante la represión de la huelga del año 1921. Castro.

Martinic, M. (1999). La inmigración chilota en Magallanes. Apreciaciones sobre sus causas, características y consecuencias. Anales del Instituto de la Patagonia, 27, 27-47.

Montiel, F. (2010). Chiloé. Historia de viajeros. Ilustre Municipalidad de Castro.

Moreno, M. (s.f.). La influencia de los chiloenses en la Patagonia. Manuscrito no publicado facilitado por el autor.

Pollak, M. (2006). Memoria, olvido, silencio. La producción social de identidades frente a situaciones límite. La Plata: Ediciones al Margen.

Urbina, R. (1988). Chiloé. Foco de emigraciones. En Chiloé y su influjo en la XI Región, II Jornadas Territoriales (pp. 31-46). Santiago: Colección Terra Nostra, 12. 
